\title{
Entre o ideário nacional da educação preparatória e os preceitos escolanovistas de Heloísa Marinho: o início da educação infantil pública de Florianópolis em 1976
}

Resumo: A presente pesquisa situa-se na área da História da Educação, mais especificamente, na história do currículo, e tem como objeto central o documento "Projeto Núcleos de Educação Infantil" de 1976, que implantou a educação infantil no município de Florianópolis (Santa Catarina/Brasil). Trata-se de estudo historiográfico em andamento, motivado pela implantação dos documentos curriculares atuais em interface com esse primeiro documento para efeito de aprofundamento do conhecimento sobre o início da educação infantil dessa rede. Sob a tutela do Programa Nacional de Educação Pré-Escolar - lançado pelo MEC em 1975 - o Projeto Núcleos de Educação Infantil previa uma pré-escola de caráter preparatório, ao mesmo tempo que sob o ideário escolanovista de Heloísa Marinho, orientava para um trabalho em que não houvesse dirigismo, e sim, respeito ao ritmo da criança, vindo a configurar-se como um currículo com pontos de tensão nas orientações da prática das primeiras professoras da educação infantil pública municipal. As fontes documentais foram analisadas à luz da história do currículo, que permite ver seu conhecimento corporificado como artefato social, histórico e cultural, com a contribuição dos estudos de Tomaz Tadeu da Silva (1995) e as fontes orais, a partir dos estudos de Paul Thompson (1992) que entende a história oral como possibilidade de revelar outros campos de investigação, como também evidenciar os sujeitos que vivenciaram a história.

Palavras-Chave: Docência em educação infantil. Currículo. Memórias de docentes 


\title{
Between ideation national preparatory education and precepts new school Heloísa Marinho: the beginning of public education of children in Florianópolis 1976
}

\begin{abstract}
The present research lies in the area of History of Education, more specifically, in the history of the curriculum, and has as its central object the document "Draft Early Learning Centers" 1976, which implemented early childhood education in Florianópolis (Santa Catarina / Brazil). This is historiographical ongoing study, motivated by the implementation of the current curriculum documents interface with this first document for the purpose of increasing knowledge about the early childhood education that network. Under the tutelage of the National Preschool Education - launched by the MEC in 1975 the Centers for Early Education Project provided for a pre - school preparatory character, while under the ideas of New School Heloísa Marinho, heading toward a work in that there was dirigisme, and yes, as the pace of the child, been set yourself up as a curriculum voltage points in the guidelines of the practice of the first teachers of the municipal early childhood education. The documentary sources were analyzed in the light of the history curriculum , which allows you to view your embodied knowledge as a social artifact, historical and cultural, with the contribution of studies Tomaz Tadeu da Silva (1995) and oral sources, from the studies of Paul Thompson ( 1992 ) believes that oral history as a possibility to reveal other fields investigation but also highlight the subjects who experienced the story. Key words: Teaching in early childhood education. Curriculum. Memories of teachers.
\end{abstract}


1 presente pesquisa situa-se na área da História da Educação, mais especificamente, na história Infantil" de 1976, que implantou a educação infantil no município de Florianópolis (Santa Catarina/Brasil). Trata-se de estudo historiográfico em andamento, motivado pela implantação dos documentos curriculares atuais ${ }^{3}$ em interface com esse primeiro documento para efeito de aprofundamento do conhecimento sobre o início da educação infantil dessa rede. A Rede Municipal de Educação Infantil de Florianópolis (RMEI) data de 1976, com a inauguração do primeiro Núcleo de Educação Infantil - NEI -, atendendo a 92 crianças (OSTETTO, 2000, p. 105). Conta, atualmente ${ }^{4}$, com 81 unidades, 32 das quais núcleos de educação infantil (NEIs), com atendimento em período parcial, e 49 creches, com atendimento em período integral. No total, são atendidas 10.695 crianças.

Na RMEI há registro de três documentos curriculares anteriores aos atuais: "Currículo PréEscolar", de 1981; "Programa de Educação Pré-Escolar", de 1988, e "Traduzindo em ações: das diretrizes a uma proposta curricular - Educação Infantil”, de 1996. A escolha do documento Projeto Núcleos de Educação Infantil, de 1976, da então Secretaria de Educação, Saúde e Assistência Social $\left(\right.$ SESAS $^{5}$ se deveu, em especial, a um depoimento oral localizado no livro de Luciana Esmeralda Ostetto (2000), Educação Infantil em Florianópolis: Retratos Históricos da Rede Municipal (19761996). Pareceu-nos muito relevante a alusão ao livro Vida e Educação no Jardim de Infância, de Heloísa Marinho, como "a nossa bíblia”, na criação dessa rede e, a partir daí, conhecer melhor o Projeto Núcleos de Educação Infantil (SESAS, 1976), como documento curricular e sua influência na prática das primeiras professoras.

No levantamento das pesquisas ${ }^{6}$ sobre a rede em Florianópolis, constatou-se escassez de produção científica nos cursos de pós-graduação na linha da história e da historiografia. O primeiro e único estudo específico nessa linha é o de Ostetto ${ }^{7}$ (já citado), por meio do qual, no que se refere à utilização de dados históricos dessa rede, pode-se afirmar ser referência, o que confirma a particularidade da sua pesquisa. Kuhlmann Jr. (1998) alerta sobre a desvalorização da educação infantil nas pesquisas educacionais, em especial na linha da história, mesmo entre os profissionais da 
área. Observa que, no geral, "os estudos privilegiam outras áreas" e a história "seria útil apenas para compor um quadro de referência” (p. 5). Rocha (2000), ao falar da pesquisa histórica das instituições de educação infantil, refere-se a uma "demanda fundamental da área da Educação" e acredita que a “compreensão das dimensões sociais, políticas e educativas que as creches e pré-escolas assumem hoje exige que se conheçam as funções sociais, as motivações políticas e orientações pedagógicas que lhes deram origem" (p. 17).

Desenvolvemos esta pesquisa à luz da história do currículo, que permite ver seu conhecimento corporificado como artefato social, histórico e cultural, que "não pode se deter na descrição estática do passado, mas deve tentar explicar como esse determinado artefato veio a se tornar o que é, descrevendo a dinâmica social que moldou dessa forma” (SILVA, 1995, p. 8). Neste sentido, o autor alega que, ao estudar o currículo de determinada época, deve-se tentar descobrir que valores, conhecimentos e habilidades foram considerados como legítimos e igualmente apontar como essa legitimidade foi constituída. Utilizaremos O Projeto Núcleos de Educação Infantil (SESAS, 1976) para evidenciar o que nele foi legitimado e transposto para a prática das primeiras professoras.

As entrevistas aqui utilizadas são originárias das pesquisas de Ostetto (2000) e Waltrick (2008). Esses depoimentos são revisitados sob outros ângulos, num caminho conjunto com outras reflexões teóricas, no sentido de evidenciar partes da história sobre essa rede, ainda não reveladas, a saber, sobre a constituição da docência na educação infantil.

[...] a história oral pode certamente ser um meio de transformar tanto o conteúdo quanto a finalidade da história. Pode ser utilizada para alterar o enfoque da própria história e revelar novos campos de investigação; [...] pode devolver às pessoas que fizeram e vivenciaram a história um lugar fundamental, mediante suas próprias palavras (THOMPSON, 1992, p. 22).

O Projeto Núcleos de Educação Infantil (SESAS, 1976): entre a educação preparatória e os princípios escolanovistas de Heloísa Marinho

Mesmo não sendo considerado um documento curricular pela RMEI, o Projeto Núcleos de Educação Infantil (SESAS, 1976) refere-se a uma "programação" e utiliza o termo "currículo" para se referir a diferentes temáticas contempladas na pré-escola ${ }^{8}$. Escrito em 14 páginas, delimita: finalidade; justificativa; objetivos; metas e área de influência; condições de execução (coordenação geral, coordenação executiva, prazos de execução, sistemática de ação); recursos (espaço físico, especificações espaço físico por unidade, material, recursos humanos por unidade, recursos financeiros por unidade, recursos financeiros por fonte e cronograma de desembolso) e controle e 
avaliação do projeto. Na parte intitulada Sistemática de Ação, define a clientela a ser atendida, os critérios de seleção, a programação a ser desenvolvida e a filosofia do pré-escolar. Este projeto deixa bem clara a destinação da educação pré-escolar pública em Florianópolis: atendimento das crianças “entre os mais carentes social e economicamente" (SESAS, 1976, p. 5). É uma proposta demarcada pelo caráter preparatório, ou seja, preparar a criança para o ingresso na escola e também pelo o que é conhecido no sistema educacional como educação compensatória, a saber, que "sob o nome de «educação compensatória» foram elaboradas propostas de trabalho junto às creches e pré-escolas defendendo a estimulação precoce e o preparo para a alfabetização (OLIVEIRA, 1988, p. 49). Souza (1984, p. 49) analisa a proposta oficial do pré-escolar no Brasil em suas linhas de ação teóricometodológicas, a partir da educação compensatória como "antídoto" para a argumentação da “privação cultural"”. O caráter preparatório do Projeto Núcleos de Educação Infantil é encontrado na justificativa da proposta: "o fato de o ensino pré-escolar estar sendo tratado como necessidade prioritária frente aos altos índices da repetência verificados nas primeiras séries do $1^{\circ} \mathrm{grau}$, atingindo, no âmbito nacional, níveis considerados alarmantes" (SESAS, 1976, p. 2), como também nos objetivos: "Preparar as crianças para realizar, satisfatoriamente, a aprendizagem na escola primária, através de seu desenvolvimento sensorial, motor e intelectual" (SESAS, 1976, p. 3). É importante ressaltar que esse projeto é criado na década de 1970, quando ocorre uma movimentação do governo federal em prol da expansão da pré-escola pública no Brasil ${ }^{10}$. Identificamos nesse projeto o que sugeriam Ostetto (2000) e Steininger ${ }^{11}$ (2009): uma forte vinculação com as prerrogativas nacionais de uma educação pré-escolar preparatória, por ocasião dessa grande expansão, destinada às crianças de famílias econômica e socialmente carentes. Este é o "cenário": um ideário nacional, parte de uma “dinâmica social” bem definida, que, como já vimos em Silva (1995), nesse caso molda a forma desse currículo, destinado às crianças “carentes”, com o objetivo de provê-las de habilidades preparatórias. Nesse sentido, é importante indicar que o Colégio Coração de Jesus ${ }^{12}$ teve influência direta sobre este projeto, tanto na sua elaboração (com a participação efetiva de uma professora que lá trabalhava), quanto na implantação (visto que a coordenadora responsável por essa implantação e as primeiras professoras são egressas dessa instituição) (OSTETTO, 2000), o que demarca ainda mais o "cenário" em que foi produzido.

O Projeto Núcleos de Educação Infantil (SESAS, 1976) implanta uma pré-escola de caráter preparatório e, ao mesmo tempo, em sua programação, faz a defesa de "vivências e não aulas a serem ministradas e repetidas" (SESAS, 1976, p. 5), o que localizamos também em outra assertiva, que recomenda: "Evitar-se-á o dirigismo e o aceleramento do processo evolutivo. Assim sendo, não haverá treinamento nem aprendizagem dirigida pelo adulto" (SESAS, 1976, p. 6). Esta orientação nos leva a acreditar que, a partir daí, o projeto expõe pontos de tensão e formas particulares de 
apropriação na prática das professoras, que tanto precisa ser diretiva, em função do caráter preparatório, quanto não-diretiva, conforme orientação dessa mesma proposta. Neste sentido, ao analisar o documento, conseguimos percebê-lo não somente "como resultado de um processo social necessário de transmissão de valores, conhecimentos e habilidades, em torno dos quais haja um acordo geral, mas como um processo constituído de conflitos e lutas entre [...] diferentes concepções sociais"13 (SILVA, 1995, p. 8). É sobre a contradição, em especial na defesa do "não-dirigismo", que trazemos para a discussão do projeto inicial da RMEI de Florianópolis o livro "Vida e Educação no Jardim de Infância" ${ }^{14}$, de Heloisa Marinho e os ideais da "Escola Nova" ${ }^{15}$.

Este projeto de 1976, da Sesas, não faz menção ao livro dessa autora, nem como material norteador a ser utilizado pelas professoras, nem como referência bibliográfica. Contudo, ao localizar o livro Vida e Educação no Jardim de Infância (MARINHO, 1967), ${ }^{16}$ encontramos uma primeira e importante evidência de que os ideais escolanovistas, presentes no Projeto Núcleos de Educação Infantil, decorrem do pensamento da educadora, visto que a programação dessa proposta é um excerto extraído do seu livro:

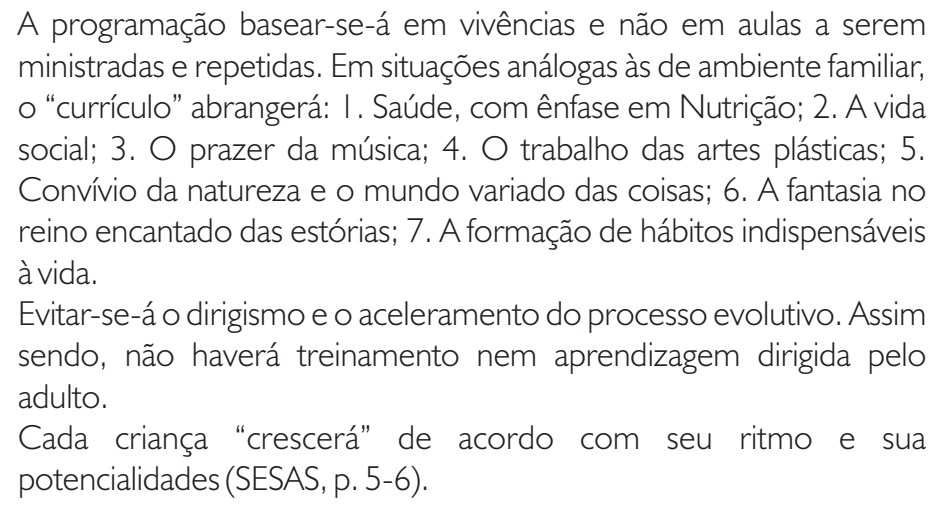

Neste extrato, também é clara a vinculação da programação com os princípios da Escola $\mathrm{Nova}^{17}$ e com o pensamento dessa autora, a saber, quando prioriza as vivências, o respeito ao ritmo, ao processo evolutivo e à potencialidade da criança, princípios defendidos e recomendados, com recorrência, por Heloísa Marinho ao longo de todo o livro Vida e Educação no Jardim de Infância.

Como Heloísa Marinho, “a educadora das educadoras” dos jardins de infância do Rio de Janeiro, chega a Florianópolis

Heloísa Marinho nasceu em 1903, na cidade de São Paulo, e faleceu em 1994, no Rio de Janeiro "[...] foi a educadora de quase todas as educadoras dos Jardins de Infância na cidade do Rio de Janeiro, no período que vai de 1934 até 1978” (LEITE FILHO, 1998, p. 5). Formou-se professora primária em 1923, no Curso Normal do Colégio Bennett (RJ) e, segundo suas próprias palavras, os 
ideais da "renovação" estão presentes na sua formação inicial, advindos da Universidade de Chicago, onde mais tarde iria estudar:

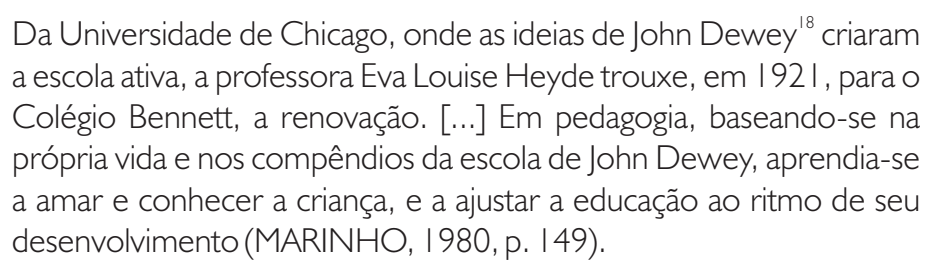

Em 1928, concluiu o bacharelado em Psicologia e a especialização em Filosofia pela Universidade de Chicago (EUA). De volta ao Brasil, em 1934, começou a lecionar no Instituto de Educação do Rio de Janeiro (IERJ) como professora assistente do professor Lourenço Filho ${ }^{19}$ (LEITE FILHO, 1997).

Primeiro livro de Heloísa Marinho ${ }^{20}$, Vida e educação no Jardim de Infância é a "obra que melhor explicita o seu pensamento pedagógico como um todo, tendo sido inclusive utilizada como guia de trabalho por muitas professoras da pré-escola do Rio de Janeiro" (LEITE FILHO, 1997, p. 108, grifos meus). Este primeiro livro foi organizado por ela em 1952:

Nas livrarias eram quase inexistentes os bons livros sobre o assunto. Uns que outros encontrados, eram escritos em idioma estrangeiro e, portanto, inacessíveis à maioria dos professores. No campo oficial, nada havia [...]. Decidimos, então, com a colaboração de elementos altamente qualificados do magistério carioca, elaborar um ProgramaGuia [...](SILVEIRA, 1967, p. 8, grifos meus).

A citação, extraída do livro Vida e Educação no Jardim de Infância, aproxima-se do depoimento oral da coordenadora responsável pela implantação do Projeto Núcleos de Educação Infantil (SESAS, 1976) sobre a relevância do livro e da autora na educação pré-escolar:

\footnotetext{
O que eu conhecia do pedagógico era a teoria da OMEP' ${ }^{21}$, baseada na Heloísa Marinho. Ela tinha um livro chamado: "Vida e educação no jardim de infância. Ela era uma professora, era uma psicóloga [...] e ali naquele livro tinha todo o embasamento pedagógico, todas as atividades, a organização de uma sala de aula, era um livro que era o nosso guia (WALTRICK, 2008, p. 76, grifos meus).
}

O pioneirismo de Heloísa Marinho no campo da educação infantil mescla-se à própria história da pré-escola do Rio de Janeiro (LEITE FILHO, 1997) e, por que não dizer, para além dessa fronteira, o que é constatado no depoimento da coordenadora do projeto, que evidencia o alcance dessa obra na educação pré-escolar de Florianópolis e a partir dos cursos da Organização Mundial de Educação Pré-Escolar (OMEP). Acreditamos que o alcance do livro Vida e Educação nos Jardins de Infância também se deva, em especial, ao fato de ser um guia prático. Nesses dois depoimentos, 
também localizamos a pouca produção e publicação na área da pré-escola à época, o que marca a particularidade e importância desse livro. Podemos ainda destacar que, de amplo alcance, só há publicações oficiais por parte do então Ministério da Educação e Cultura (MEC) ${ }^{22}$, na segunda metade da década de 1970, por ocasião da expansão do atendimento pré-escolar no Brasil. Outra evidência de sua influência como "guia prático" está na introdução da terceira edição, escrita por Lourenço Filho, que se soma às duas citações anteriores ao considerar a obra um "guia" para as professoras da pré-escola no País:

\footnotetext{
É, na verdade, um guia prático que conduz à reflexão. Poderá assim atender aos desejos de um grande número de mestras que se ocupam em nossas instituições de educação pré-escolar [...]. Acentuando o desejo de maior estudo sobre os problemas das primeiras idades, seguramente contribuirá para o progresso da educação pré-escolar em nosso país (LOURENÇO FILHO, I967, p. I 5, grifos meus).
}

Em todo o livro, os princípios escolanovistas recomendados por Heloísa Marinho são facilmente identificados: no desenvolvimento das reflexões sobre a criança, nas atividades propostas para o jardim de infância e nas recomendações de posturas a serem adotadas pelas professoras, a exemplo do que a autora recomenda, ao enfatizar que as atividades "sejam orientadas no sentido: a) do estímulo à atividade espontânea e ao trabalho criativo; b) do respeito e atendimento às diferenças individuais, pela convicção de que se há de adaptar as atividades à capacidade e ao nível de cada criança” (MARINHO, 1967, p. 142).

A pergunta que então fizemos é como esse livro chega a Florianópolis, cruzando as fronteiras do Rio de Janeiro? Um primeiro indicativo é que tenha vindo pelas mãos da coordenadora contratada para implantar o Projeto Núcleos de Educação Infantil (SESAS, 1976), egressa do Colégio Coração de Jesus, que, em depoimento oral, destaca sua experiência e conhecimento sobre a pré-escola, ao contrário do que encontrou na prefeitura municipal de Florianópolis: “Gente! Foi tão difícil fazer esse pessoal aprender o que era pré-escola... inicialmente eu me sentia uma ave fora do ninho" (OSTETTO, 2000, p. 46) e que, como já vimos, se referiu ao livro como "bíblia" e "guia". Egressa desse colégio e à frente da proposta de implantação do pré-escolar municipal, já como coordenadora, contratou as primeiras professoras da rede do referido colégio sob a justificativa de terem formação específica ${ }^{23}$ na área - o curso materno-infantil. Na década de 1970, época da criação da RMEI, o Colégio Coração de Jesus era referência na formação de professoras, pois, além do Curso do Magistério, também oferecia o Curso Técnico de Materno-Infantil ${ }^{24}$. Por isso, muito provavelmente, o livro tenha vindo desse colégio, através do próprio curso Materno-Infantil e pelas mãos da coordenadora, por ter sido considerado um "guia prático" e, pela mesma razão, em particular pela escassez de publicações na área da pré-escola. 


\section{Considerações finais}

O Projeto Núcleos de Educação Infantil de 1976, como primeiro documento orientador da prática das primeiras professoras, configura pontos de tensão e formas particulares de apropriação na medida em que a proposta comporta, juntamente com o ideário escolanovista, o caráter de uma educação preparatória. Esta contradição no documento de 1976 comprova, por si só, este ponto de tensão, que é então potencializado se pensarmos na possível influência direta do próprio livro Vida e Educação no Jardim de Infância, tomado como "bíblia" ou "guia", o qual, permeado por importantes elementos - concepções, teorias, orientações de práticas pedagógicas -, consideramos ter influenciado a produção de um jeito de ser professora de educação infantil nessa rede. Admitida tal interpretação, SILVA (2002, p. 150) afirma que "currículo é autobiografia, nossa vida, curriculum vitae: no currículo se forja nossa identidade. O currículo é texto, discurso, documento", que pode, então, forjar a identidade desse profissional.

No depoimento de uma das primeiras professoras dessa rede, pode-se localizar um "ponto de tensão": "Tinha um planejamento e tinha também uma preocupação com a primeira série [...]. O planejamento, no seu conteúdo, já dava uma pequena preparação. Eles não saíam alfabetizados... mas a gente dava aquela noção pra primeira série (OSTETTO, 2000, p. 115), ou seja, ao invés de "preparar" a criança para o ensino de $1^{\circ}$ grau, as professoras davam "uma pequena preparação", uma “noção pra primeira série". Tal postura é assumida possivelmente em função do documento de 1976, que recomendava que não houvesse "treinamento nem aprendizagem dirigidos pelo adulto", para respeitar o "ritmo" da criança e "suas potencialidades" (SESAS, 1976, p. 6) como também, provavelmente, por influência desse livro "guia".

Ao assumir um modo de aprendizagem que nem tanto "prepara" a criança para a primeira série, como também não deixa de oferecer uma "pequena preparação", fica clara a adequação, na prática dessas professoras, a esse "ponto de tensão" do documento de 1976, que oscila entre "dirigir" e "não-dirigir" a aprendizagem das crianças. Neste sentido, atendem ao proposto no Projeto Núcleos de Educação Infantil, moldam sua prática, mesmo que também contraditória.

Os documentos curriculares podem ser considerados como um contributo à produção do modo de ser professor, num processo “identitário”, como indica Nóvoa (2007, p. 16): a “identidade é um lugar de lutas e de conflitos, é um espaço de construção de maneiras de ser e de estar na profissão. Por isso, é mais adequado falar em processo identitário”. Podemos, neste sentido, entender que o currículo também contribui na formação do habitus pedagógico, entendido como modo de pensar e agir do professor, “[...] cujas características estão relacionadas ao que o/a professor/a vivenciou, ouviu, praticou e reproduziu, a partir das representações construídas sobre e no processo de ensino 
escolarizado" (TEIVE, 2008, p. 26).

Sob a perspectiva desses autores, percebemos que documentos curriculares, além de orientarem a prática de professores, também contribuem para a produção de um determinado habitus $^{25}$, entre o que eles praticam e reproduzem, entre o que entendem "ser e estar" nessa profissão, entre o que é propugnado nos documentos e o que é incorporado à sua prática pedagógica. Esta pesquisa mostra como o pensamento de Heloísa Marinho, que se sustenta nos ideais escolanovistas, transpôs as fronteiras do Rio de Janeiro, chegando à RMEI de Florianópolis por meio da obra Vida e Educação no Jardim de Infância, demarcando, de forma particular, o início da educação pré-escolar pública com sua inserção no Projeto Núcleos de Educação Infantil (SESAS, 1976). Consideramos que este documento não foi tão somente decisivo na implantação de um sistema pré-escolar, como, sobretudo, na estruturação de uma prática pedagógica e na constituição da identidade das primeiras professoras dessa rede. 
3. Diretrizes Educacionais Pedagógicas para a Educação Infantil (SME, 2010) e Orientações Curriculares (no prelo).

4. Dados de setembro de 2011, fornecidos pela Diretoria do Observatório da Educação e Apoio ao Educando (DIOBE) da Secretaria Municipal de Educação de Florianópolis.

5. Inicialmente, a educação estava a cargo da Secretaria de Educação, Saúde e Assistência Social (SESAS), juntamente com outros setores. A partir de 1985, houve o desmembramento, passando a ser Secretaria Municipal de Educação (SME) (OSTETTO, 2000).

6. A Universidade Federal de Santa Catarina (UFSC) foi tomada como referência na busca de pesquisas na área da educação infantil, por manter linha de pesquisa na área da infância - Educação e Infância - e por ter sido localizada no seu programa de pós-graduação a maior concentração de pesquisas sobre a Rede Municipal de Educação Infantil do município de Florianópolis (SC). Foi utilizado como fonte o site http://www.ced.ufsc.br/nupein/, do Núcleo de Estudos e Pesquisas da Educação na Pequena Infância (NUPEIN). Acesso em: 13 out. 2011.

7. Professora do Centro de Educação - Universidade Federal de Santa Catarina, com doutorado em Educação pela Universidade Estadual de Campinas (2006), mestrado em Educação pela Universidade Federal de São Carlos (1992) e graduação em Pedagogia pela Universidade Federal de Santa Catarina (1985). No âmbito das atividades acadêmicas, articula ensino, pesquisa e extensão na área de Educação, com ênfase em Formação de professores e Educação Infantil, contemplando, principalmente, os seguintes temas: educação infantil e prática pedagógica, arte e infância, arte e formação de professores (PLATAFORMA LATTES, 2012). Acesso em: 13 mar. 2012. O referido livro de Ostetto não é uma pesquisa de pós-graduação.

8. No final de 1980, período da possível vigência do documento Projeto Núcleos de Educação Infantil, a RMEI contava com 5 NEIs e 1 creche, atingindo o atendimento de 530 crianças (OSTETTO, 2000).

9. Para Kramer (1982, p. 35) a argumentação da privação cultural "postula que existe uma estreita relação entre o desenvolvimento da criança e sua origem socioeconômica, e que as causas de variações no desenvolvimento devem ser procuradas nas desigualdades culturais das famílias, estabelecidas a partir da classe social a que pertencem". Sobre o ideário da privação cultural no Brasil, ver Campos (1985) e Rosemberg (2002).

10. Ver estudos de Souza (1984), Oliveira (1988) e Rosemberg (1999).

11. Steininger (2009), em sua pesquisa sobre a RMEI, analisa os documentos oficiais publicados no Brasil na segunda metade da década de 1970 pelo então Ministério da Educação e Cultura (MEC).

12. O Colégio Coração de Jesus era uma instituição escolar da rede privada, de caráter confessional, católico, fundada em 1898. Foi referência na educação florianopolitana e catarinense, não só na formação discente, mas, em especial, na formação de professores. Em 1919, o Curso Complementar, anexo ao colégio, foi equiparado ao da Escola Normal Catarinense. Forma a sua primeira turma de normalistas em 1921. O colégio também foi referência no atendimento pré-escolar, tendo criado o Jardim de Infância em 1914 (BOPPRÉ, 1989).

13. Num dos documentos publicados pelo MEC, na época, Educação Pré-escolar - uma nova perspectiva Nacional (Brasil, 1975), também são percebidas concepções contraditórias.

14. Em 1952, é publicada a primeira edição do livro Vida e educação no jardim de infância, de Heloisa Marinho - título identificado com o livro de Dewey - Vida e Educação - que, na segunda e terceira edição (1960 e 1966), foi o título do primeiro capítulo do livro (KUHLMANN JR., 2000, p. 9).

15. O movimento das "Escolas Novas", tensionado pelas transformações sociais de uma época - no período das duas Grandes Guerras Mundiais -, foi impulsionado pelo ideário de transformação da escola vigente - "a tradicional" - e pelos estudos crescentes de biologia, sociologia e, principalmente, de psicologia, aplicados à educação. A escola nova, de abrangência internacional, enquanto "movimento pedagógico, fez-se sentir com intensidade até a segunda Guerra Mundial (1939-1945). Após seu desaparecimento como organização internacional, não houve outro movimento comparável nesse nível" (DUSSEL, CARUSO, 2003, p. 192). Os ideais escolanovistas tiveram grande projeção no âmbito das 
discussões educacionais: "Em vários países, muitos educadores [...] experimentaram variar os procedimentos de ensino, ou logo transformar as normas tradicionais da organização escolar, com isso ensaiando uma escola nova, no sentido de escola diferente das que existissem (LOURENÇO FILHO, 1978, p. 17).

16. Ostetto (2000), Waltrick (2008) e Steininger (2009) não falam da localização e estudo desse livro em suas pesquisas.

17. Lourenço Filho (1978, p. 246-248), um dos intelectuais expoentes da Escola Nova no Brasil indica alguns princípios desse movimento: "o respeito à personalidade do educando ou o reconhecimento de que deverá ele dispor de liberdade", do qual decorre o combate ao aspecto impositivo da educação tradicional; um segundo princípio "resulta da compreensão funcional do processo educativo, quer sob o aspecto individual, quer social", ao considerar que o processo educativo "se dá no tempo, por crescimento e maturação", sendo a expressão lúdica de "um ponto de partida"; o terceiro princípio, sobre "a compreensão simbólica em situações de vida social", indica que qualquer situação de ensino "é sempre de cooperação social", aspecto desprezado pela escola tradicional e, assim, "a renovação propugna no sentido de que a escola, ela própria, se organize como uma pequena comunidade" e, ainda, como um princípio final, "qual seja, o de que as características de cada indivíduo serão variáveis", sendo o homem, "em grande parte, expressão do meio cultural" ou das condições de vida.

18. John Dewey (1859-1952) “exerceu grande influência na pedagogia contemporânea. Foi talvez, o pensador mais importante da Escola Nova. [...] (LEITE FILHO, 1998, p. 30). Froebel fundou os jardins de infância no final do século XIX - os Kindergartens -, que serviram de modelo institucionalizado à educação pré-escolar. Seus preceitos ainda hoje estão presentes na educação infantil. Froebel teve o cuidado de evitar a palavra "escola", para diferenciar sua instituição destinada às crianças pequenas das instituições escolares (ARCE, 2002). Pestalozzi (1746-1827) e Froebel (1782-1852) são considerados precursores do ideário da Escola Nova, inspirados nas ideias de Rousseau (1712-1778).

19. Lourenço Filho e Anísio Teixeira, juntamente com Fernando de Azevedo, ficaram conhecidos como "os cardeais da educação nacional". Foram "companheiros de luta no movimento de renovação educacional do País" e signatários do Manifesto dos Pioneiros da Educação Nova, em 1932 (http://www.dominiopublico.gov.br/download/texto/me0000323.pdf. Acesso em: 25 jul. 2011.

20. Essa primeira edição foi organizada juntamente com um grupo de professoras que estavam à frente do Departamento de Educação Primária (DEP) do Rio de Janeiro, pela necessidade de sistematização do trabalho e orientação das professoras que trabalhavam nos jardins de infância (MARINHO, 1967).

21. A OMEP, organização internacional, não-governamental, foi fundada em 1948. "Em 1952, educadores brasileiros, que participaram, no México, do $4^{\circ}$ Congresso da OMEP, de lá voltaram entusiasmados com a ideia de implantar a organização, aqui no Brasil" (FERREIRA \& PERIM, 2003, p. 21). A OMEP, que chegou ao Brasil na década de 50, "atuou e continua atuando na elaboração e implantação de educação pré-escolar [...] do Brasil, que, entre outras ações, realiza periodicamente congressos no país (ROSEMBERG, 1992, p. 22).

22. Steininger (2009) destaca a publicação de três documentos específicos: Diagnóstico Preliminar da Educação Pré-Escolar no Brasil (BRASIL, 1975), Educação Pré-Escolar - uma nova Perspectiva Nacional (BRASIL, 1975) e Atendimento ao Pré-Escolar (BRASIL, 1977).

23. Ostetto (2000) chama a atenção para a contratação de professoras com formação específica na RMEI, o que implica uma diferença em relação a outros municípios brasileiros, por ocasião da expansão da préescola no Brasil na década de 1970, baseada em programas de baixo custo. Sobre esses programas de baixo custo, recomendados por organismos internacionais, e a implicação na contratação de pessoas leigas para a pré-escola, ver Rosemberg (2002).

24. Em visita ao Arquivo Histórico do Colégio Coração de Jesus, foram localizados, nas pastas Concluintes Materno Infantil, os registros do curso de 1974 até 1979. Em 1967, há registro de um Curso Intensivo de Jardim de Infância realizado no período das férias de julho e, no ano de 1973, o registro de um Curso para Professor Pré-Primário, no período das férias de janeiro e fevereiro. 
25. A noção de habitus está presente nas diversas obras do sociólogo francês Pierre Bourdieu. Dentre elas: A Reprodução, escrita com a parceria Jean Claude Passeron; O Poder Simbólico; Economia das Trocas Simbólicas. 
Fontes Documentais

Florianópolis. (1976). Programa Educação Pré-Escolar no município de Florianópolis: Projeto Núcleos de Educação Infantil. Prefeitura Municipal de Florianópolis. Secretaria de Educação, Saúde e Assistência Social. . (2010). Diretrizes educacionais pedagógicas para educação infantil. Florianópolis: SME/PMF. No prelo: Gráfica \& Editora Ltda.,

Ministério da Educação e Cultura. (1975). Educação Pré-Escolar - uma nova perspectiva Nacional. Brasília: Departamento de Ensino Fundamental. Coordenação de Educação PréEscolar.

Referências

Arce, A. (2002) Friedrich Froebel: o pedagogo dos jardins de infância. Petrópolis: Vozes, Boppré, M. R. (1989). O Colégio Coração de Jesus na Educação Catarinense. Florianópolis: Lunardelli.

Campos, M. M. M. (1985). In: Cad. Pesq., São Paulo (53): 21-24, maio. Pré-escola: entre a educação e o assistencialismo.

Dussel, I. e Caruso, M. (2003) A invenção da Sala de Aula: Uma Genealogia das Formas de Ensinar. São Paulo: Moderna.

Ferreira, M. O. S \& Perim, M. L. F. (2003). (Orgs.). A História da OMEP no Brasil(1953 -2003): Educação Infantil. Rio de Janeiro: Ravil Editora.

Leite Filho, A. G. (1997). Educadora de Educadoras: Trajetória e ideias de Heloísa Marinho. Uma História do Jardim de Infância no Rio de Janeiro. Rio de Janeiro. Dissertação de Mestrado, Pontifícia Universidade Católica do Rio de Janeiro.

(1998) Heloísa Marinho: Educadora de educadoras na educação infantil do Rio de Janeiro. Disponível em <http://168.96.200.17/ar/libros/anped/0209P.PDF>. Acesso em: 17 jul. 2011.

Lourenço Filho, M. B. (1978). Introdução ao Estudo da Escola Nova. São Paulo: Melhoramentos. . (1967) Introdução. In: Marinho, H. Vida e Educação no Jardim de Infância. Rio de Janeiro: Conquista.

Kramer, S. (1982). A Política do Pré-Escolar no Brasil: A Arte do Disfarce. Rio de Janeiro: Achiamé.

Kuhlmann Jr. M. (1998). Infância e educação infantil: uma abordagem histórica. Porto Alegre: Mediação.

. (2000). Histórias da Educação Infantil Brasileira. Disponível em <http://www.anped.org.br/rbe/rbedigital/RBDE14/RBDE14_03_MOYSES_KUHLMANN_J R.pdf>. Acesso em: 20 jul. 2011.

Oliveira, Z. M. R. (1988) A Creche no Brasil: Mapeamento de uma Trajetória. In: R. Fac. Educ., São Paulo 14 (1): 43-52, jan./jun. 
Ostetto, L. E. (2000). Educação Infantil em Florianópolis: Retratos Históricos da Rede Municipal (1976-1996). Florianópolis: Cidade Futura.

Marinho, H. (1967). Vida e educação no jardim de infância. Rio de Janeiro: Conquista.

(1980). Currículo por atividades: no jardim de infância e escola de $1^{\circ}$ grau. Rio de Janeiro: Papelaria América.

Nóvoa, A. (2007). Os Professores e as Histórias da sua Vida. In: Nóvoa, A. (Org.). Vidas de Professores. Porto: Porto Editora.

Rocha, E. A. C. (2000). Apresentação. In: Ostetto, L. E. Educação Infantil em Florianópolis. Florianópolis: Cidade Futura.

Rosemberg. F. (2002). Organizações multilaterais, Estado e Políticas de Educação Infantil. In: Cad. Pesq. São Paulo, v. 115, p. 25-63.

. (1992). A Educação Pré-Escolar Brasileira durante os Governos Militares. In: Cad. Pesq. São Paulo, n. 82, p. 21-30. . (1999). Expansão da Educação Infantil e Processos de Exclusão. In: Cad. Pesq. São Paulo, n. 107, p. 7-40.

Silva, T. T. (2002). Documentos de identidade: uma introdução às teorias do currículo. Belo Horizonte: Autêntica.

(1995). Apresentação. In: Goodson, I. F. Currículo: teoria e história. Petrópolis: Vozes.

Silveira, J. (1967). Prefácio da 3. ed. In: Marinho, H. Vida e educação no jardim de infância. Rio de Janeiro: Conquista.

Souza, S. J. (1984). Tendências e Fatos na Política da Educação Pré-Escolar no Brasil. In: Cad. Pesq. São Paulo (51), p. 47-53.

Steininger, I. J. (2009). A prática pedagógica nas instituições de educação infantil: um estudo de caso sobre o que indicam as professoras. Dissertação (Mestrado em Educação) - UFSC Florianópolis.

Teive, G. M. G. (2008). "Uma vez normalista, sempre normalista": cultura escolar e produção de um habitus pedagógico. (Escola Normal Catarinense - 1911/1935). Florianópolis: Insular.

Thompson, Paul. (1992). A voz do passado: história oral. Rio de Janeiro: Editora Paz e Terra.

Waltrick, Rose Elaine de Liz. (2008). O coordenador pedagógico na educação infantil da rede municipal de educação de Florianópolis: marcas de uma experiência democrática. Dissertação (Mestrado) - Universidade Federal de Santa Catarina - Florianópolis. 